\title{
The insertion sequence IS200 fingerprints chromosomal genotypes and epidemiological relationships in Salmonella heidelberg
}

\author{
John Stanley, ${ }^{1 *}$ André Burnens, ${ }^{2}$ Neville Powell, ${ }^{1}$ Namoos Chowdry ${ }^{1}$ and Clive Jones ${ }^{1}$ \\ ${ }^{1}$ NCTC Molecular Genetics Unit, Central Public Health Laboratory, 61 Colindale Avenue, London NW9 5HT, UK \\ ${ }^{2}$ Swiss National Reference Laboratory for Foodborne Disease, Institute for Veterinary Bacteriology, University of Berne, \\ Langgass-Strasse 122, CH-3012 Berne, Switzerland
}

(Received 6 April 1992; revised 30 June 1992; accepted 13 July 1992)

\begin{abstract}
In Salmonella heidelberg the copy number of the Salmonella-specific insertion element IS200 was found to vary from four to six. All strains tested contained at least one common insertion site which was serovar specific, and most strains contained three common sites. Concurrent analysis of plasmids indicated that all insertion sequence copies were chromosomally located, and also supported the equivalence of an IS200 fingerprint and clonality. Seven intra-serovar clonal lines were thereby identified. One of these was associated with human infections, including septicaemias. Another was associated with chicken as a host: all these strains also carried a unique plasmid of $23 \mathrm{MDa}$, which was typed as a member of the IncX group. The chromosomal fingerprint of a third clone showed it to be a descendant of the chicken line marked by a single IS200 transposition. One or two representatives of four other clonal lines were identified. These lines of $S$. heidelberg could be related by divergent evolution, and the most recent relatives conformed to a continuous branching process model of IS200 transposition. This insertion sequence provided a highly discriminatory molecular marker of the $S$. heidelberg chromosome, and two of the seven clonal lines so identified were associated with distinct clinical/epidemiological contexts.
\end{abstract}

\section{Introduction}

Salmonella heidelberg is a Group B serovar which is consistently among the ten most common causative agents of nontyphoid salmonellosis (Harris et al., 1990; Threlfall et al., 1992). The clinical symptoms associated with $S$. heidelberg range from mild diarrhoea to severe gastrointestinal illness (Choi et al., 1990), and include septicaemic bloodstream invasion in more than $3 \%$ of cases (Threlfall et al., 1992). This can vary from a selflimiting asymptomatic infection to meningitis (AyrozaGalvao et al., 1989) or fatal bacteraemia in children (Rice et al., 1976) and immunocompromised patients (Heal et al., 1987).

For serovars of primary epidemiological or clinical importance, such as $S$. typhimurium, $S$. enteritidis or $S$. typhi, phage typing schemes have been developed which are highly discriminatory at the intra-serovar level (Threlfall \& Frost, 1990). S. heidelberg is one of a group of important serovars for which there is currently no subtyping methodology, other than profiling of plasmid

* Author for correspondence. Tel. (081) 2004400 ext. 3744; fax (081) 2007874 content. Although this has often proved a useful epidemiological marker, it is unsatisfactory for genotype analysis, because plasmids are extrachromosomal replicons which are subject to considerations of stability, lateral transfer, and host range. Hence a method for generating discriminatory molecular fingerprints of the chromosome would greatly assist the genetic analysis of evolutionary and epidemiological relationships between strains of $S$. heidelberg (and other serovars of similar importance in human and veterinary disease). The antigen profile of $S$. heidelberg $(1,4,5,12: \mathrm{r}: 1,2)$, like those of $S$. choleraesuis and $S$. typhimurium, was shown by multilocus enzyme electrophoresis to be confined to a cluster of closely related chromosomal genotypes. Eight such electrophoretic types were identified among 204 isolates (Beltran et al., 1988).

The insertion sequence IS200, specific to Salmonella spp. (Lam \& Roth, 1983), is the smallest characterized mobile DNA element. This 708 bp element (Gibert et al., 1991) lacks inverted repeats and has only very rarely been observed to transpose in the laboratory (O'Reilly $e t$ $a l ., 1990)$. In theory, the number of insertion sequences and their locations can change rapidly, and the determination of similarity or identity among strains in copy 
number and position of IS elements is strong evidence of common ancestry (Sawyer et al., 1987). In Salmonella enteritidis, IS200 differentiated strains at the intraserovar level. Both phage type strains and pandemic isolates could be classified in three evolutionary lines defined by chromosomal hybridization profiles of the element (Stanley et al., 1991, 1992b).

We have determined the copy number and profile of IS200 in a collection of $S$. heidelberg isolates. A comparative analysis of plasmid content was made. This and epidemiological background data were correlated with IS200 fingerprints. We present a genetic analysis of $S$. heidelberg, which is also of potential importance for the molecular epidemiology and molecular phylogenetics of Salmonella in general.

\section{Methods}

Bacterial strains, culture conditions and genetics. Strains of Salmonella used in this study are listed in Table 1. Clinical, food poisoning and veterinary isolates of $S$. heidelberg were from the recent investigative programme of the Swiss National Reference Laboratory for Foodborne

Table 1. Bacterial strains and probe DNAs

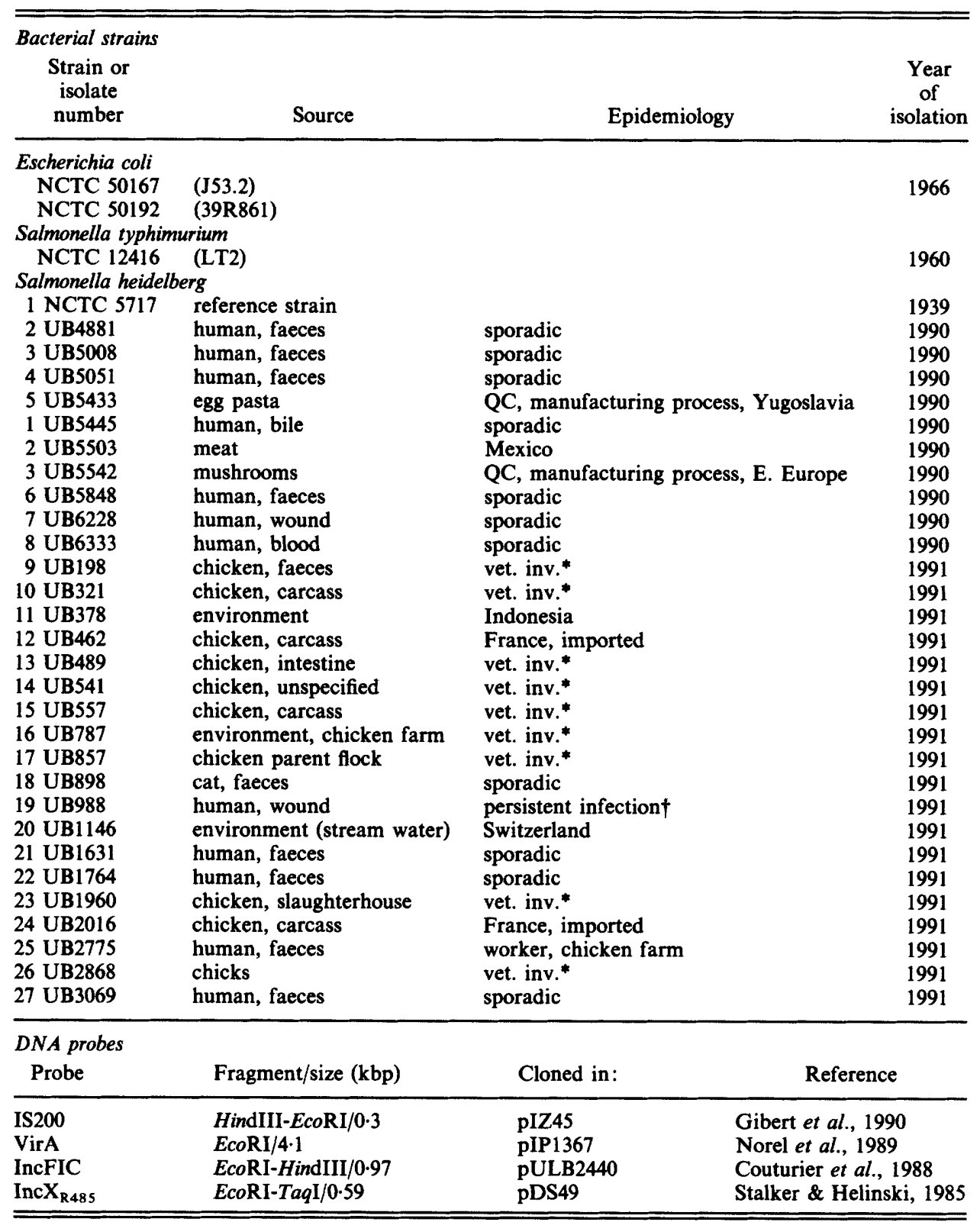

* Isolates from veterinary investigation of Salmonella carriage in broiler flocks in Switzerland in 1991.

$\dagger$ Isolate from same patient as UB6228; analysed in order to test marker stability in vivo. 
Disease. Poultry strains were collected for a study by the Swiss Federal Office of Veterinary Public Health of Salmonella carriage in broiler flocks. Strains were grown in nutrient broth/agar for DNA isolation, and purity was checked on blood agar plates. Stock cultures were maintained on Dorset-egg agar slopes. Antibiotic resistance markers were determined with susceptibility discs (Oxoid) on Isosensitest (Oxoid) agar. Resistant strains were screened for the ability to transfer antibiotic resistance to Escherichia coli J53-2, and transconjugants were screened with respect to the molecular size of acquired plasmid DNA (see below).

DNA techniques. Plasmid DNA of $S$. heidelberg was analysed by the method of Kado \& Liu (1981). Plasmid pIZ45 was isolated by alkaline lysis and purified in a $\mathrm{CsCl}$ /ethidium bromide gradient according to standard methods (Sambrook et al., 1989). The HindIII-EcoRI fragment cloned in p1Z45 was isolated by electro-elution from $1.0 \%$ agarose (Sigma; medium EEO) and labelled by random-priming (Boehringer Mannheim kit) with ${ }^{35}$ S-dATP or 16-dUTP-biotin for use as an IS 200 probe. Alternatively, the cloned insert fragment was amplified from a $620 \mathrm{bp} P v u I I$ fragment of pIZ45 by the polymerase chain reaction (PCR) employing forward and reverse sequencing primers and 16-dUTP-biotin was incorporated during PCR. The biotinylated product was subjected to centrifugal ultrafiltration (Millipore Ultrafree-MC; 30000 NMWL unit).

Genomic DNA was extracted from $S$. heidelberg by the method of Wilson (1987), and $5 \mu \mathrm{g}$ quantities were digested with one of three enzymes (PstI, BglII or HincII) which lack restriction sites within the IS200 sequence (Gibert et al., 1991). Genomic restriction digests or whole plasmid DNAs were electrophoresed in $0.7 \%$ agarose, and vacuum-blotted (LKB Vacu-gene apparatus) on to Hybond $\mathrm{N}$ nylon membrane (Amersham). Hybridization was by standard methods (Sambrook et al., 1989). Hybridized filters were washed twice with each of the following: $2 \times \mathrm{SSC} / 0.1 \% \mathrm{SDS}$ for $5 \mathrm{~min}$ at $20^{\circ} \mathrm{C}, 0.2 \times \mathrm{SSC} / 0.1 \%$ SDS for $5 \mathrm{~min}$ at $20^{\circ} \mathrm{C}$ and $0.16 \times \mathrm{SSC} / 0.1 \% \mathrm{SDS}$ for $30 \mathrm{~min}$ at $60^{\circ} \mathrm{C}$. Hybridization reactions were visualized either colourimetrically with the BluGENE (Gibco-BRL) non-radioactive nucleic acid detection system or by autoradiography using standard methods (Sambrook $e t$ al., 1989) and Hyperpaper (Amersham).

\section{Results}

\section{Analysis of IS200 insertion sites}

Genomic Southern blots were made with Pst I and BglII for all Salmonella strains listed in Table 1 and hybridized with an IS200 probe as described in Methods. PstI digests provided a clearer resolution of loci than did $B g l I I$ and were therefore used for subsequent analysis. Eleven distinct insertion sites of IS200 were detected in PstI digests. Both enzymes confirmed that all $S$. heidelberg isolates contained 4-6 insertion sites, one of which was common to all (Pst I, $1.7 \mathrm{kbp}, B g l \mathrm{II}, 2.3 \mathrm{kbp}$ ). The $1.7 \mathrm{kbp}$ PstI IS200 band is likely to be serovar specific for $S$. heidelberg, since it has not been observed in S. typhimurium, S. bovis-morbificans, $S$. paratyphi or in some twenty other serovars including $S$. enteritidis, S.berta, S. dublin, S. panama, S. napoli and S. miami (our unpublished results). Data were compared for all strains from genomic Southern blots, such as presented in Fig. 1. The molecular sizes of homologous PstI fragments were averaged from three blots and varied from $1.7 \mathrm{kbp}$ to over $30 \mathrm{kbp}$ in size.

The IS200 hybridization profile of the type strain of $S$. heidelberg, NCTC 5717, is shown in Fig. 1, track 1. This was provisionally termed IS fingerprint I since the strain isolation date (1939) pre-dated all others in this investigation. It shared a homologous $5.5 \mathrm{kbp} P$ st I fragment with all but three strains (UB4881 or UB5008, and UB378; cf. Fig. 1, tracks 6 and 7).

A similar fragment of about $20 \mathrm{kbp}$ was found in the great majority of strains in the set, i.e. in eighteen human, animal and environmental isolates. Hence all these strains shared three PstI IS 200 bands with NCTC 5717. Fifteen of the strains had been isolated from an investigative epidemiological analysis of Salmonella infection and contamination during all stages of intensive chicken farming. For example, strains UB857, UB489 and UB198 were veterinary isolates from a parent flock, from chicken gut and chicken faeces; strains UB321, UB462, UB557 and UB2016 were isolates from chicken carcasses, strain UB1960 was from a chicken slaughterhouse and strain UB2775 was isolated from a chicken-processing-plant worker reporting with gastrointestinal illness. The IS200 fingerprint of all these strains exhibited an identical copy number of five and it was termed IS 200 fingerprint II. The IS 200 profile of three other strains, UB787 (Fig. 1, track 3), UB1146 and UB2868 was termed fingerprint III, and exhibited a copy number of six : five insertion sites were common to the fifteen chicken-associated strains, and the sixth was common only to these three strains which were environmental or veterinary isolates.

Six strains exhibited an IS200 copy number of four and a profile identical to UB5445 (Fig. 1, track 4), which was termed fingerprint IV. In this, the $1.7 \mathrm{kbp}$ and $5.5 \mathrm{kbp}$ fragments were common to NCTC 5717, a third Pst I fragment of $8.6 \mathrm{kbp}$ was common to the chicken/ environmental group, and the fourth and largest PstI fragment $(\approx 30 \mathrm{kbp})$ was unique. These strains were human and food isolates, and three were from human septicaemic infections. Strains UB6228 and UB988 were isolates from the same patient, taken four months apart from a persistently infected leg wound. The identity of their IS200 fingerprint confirms its stability as a marker in vivo for group IV. A single distinct strain, UB3069 (Fig. 1, track 5) had an IS200 copy number of five, four copies being located in Pst I fragments common to the six strains just described. This related profile was termed fingerprint $\mathrm{V}$.

In all blots and with all enzymes UB4881 (Fig. 1, track 6) and UB5008, which were sporadic human gastroenteritis isolates, yielded identical and novel IS200 profiles. The Indonesian environmental isolate, UB378, exhibited yet another unique hybridization profile (Fig. 


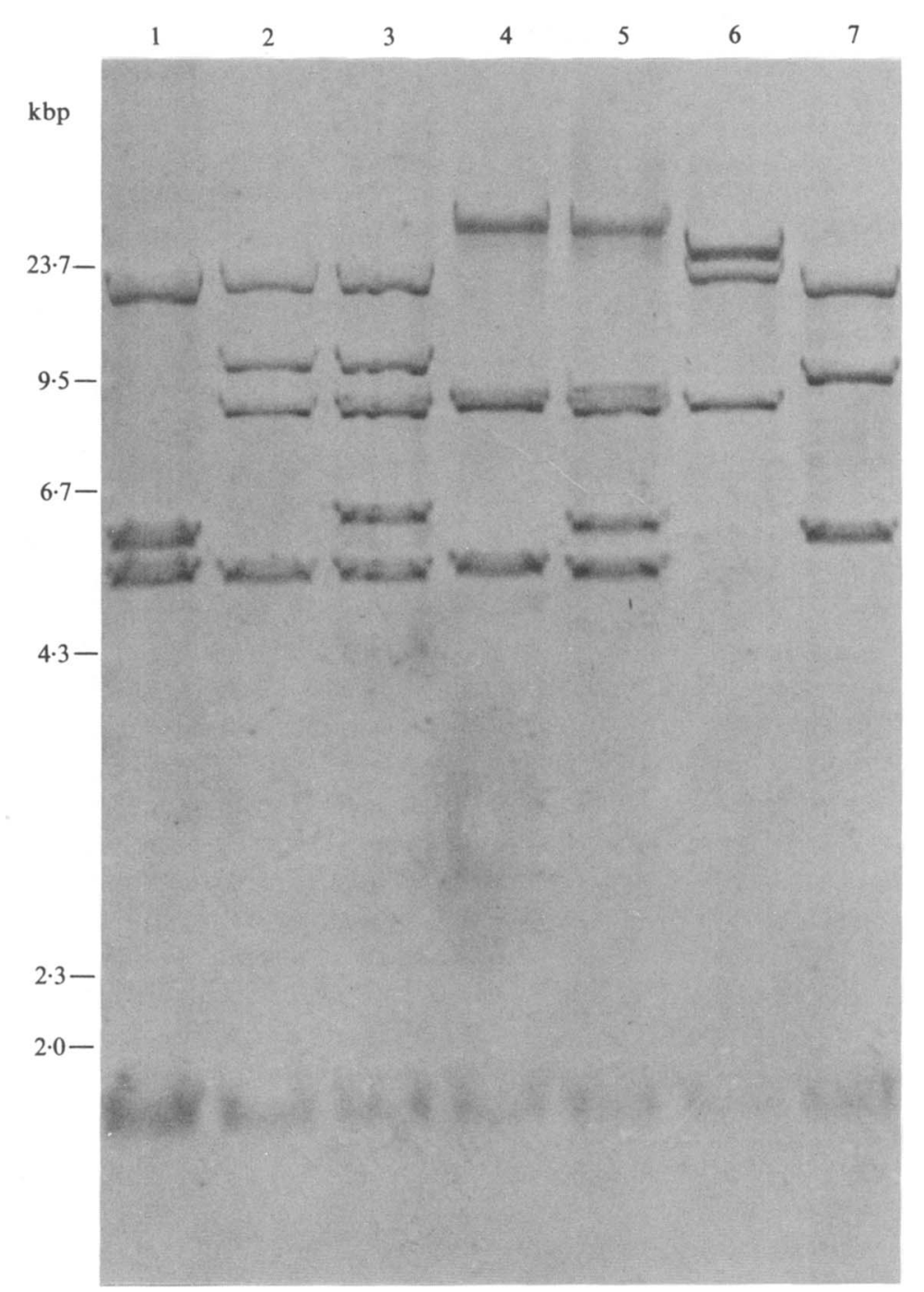

Fig. 1. IS 200 hybridization to genomic DNA of $S$. heidelberg. Genomic Southern blot made with PstI and hybridized with an internal fragment of IS 200 labelled with 16-dUTP-biotin. Tracks 1-7 contained the following strains whose origins are given in parentheses: track 1, strain NCTC 5717 (type strain); 2, UB198 (chicken); 3, UB787 (environment of chicken farm); 4, UB5445 (human, extraintestinal); 5, UB3069 (human, faecal); 6, UB4881 (human, faecal); 7, UB378 (environment).

1, track 7). A diagrammatic representation of the fingerprints of all $S$. heidelberg strains listed in Table 1 is shown in Fig. 2 (see also assignment of clonal lines, below).

\section{Plasmid analysis}

A comparison was made between IS200 fingerprinting and plasmid analysis. Strains were ordered according to their IS200 fingerprint groups, and analysed for plasmids by the method of Kado \& Liu (1981). The data are summarized in Table 2. Plasmids of seventeen sizes were detected. Four strains, belonging to three IS fingerprint groups, carried no plasmids. These were NCTC 5717, UB988, UB6228 and UB378 respectively. The plasmid size range varied from $0.8 \mathrm{MDa}$ to $120 \mathrm{MDa}$.
Ten of the thirty strains exhibited resistance to antibiotics. Only $1 / 11$ chicken strains expressed resistance (UB462: $\mathrm{Ap}^{\mathrm{R}} \mathrm{Sm}^{\mathrm{R}} \mathrm{Sp}^{\mathrm{R}}$ ), while 6/12 human, 2/3 food and one feline isolate did so. All ten strains were resistant to more than one antibiotic. One strain, from Mexico, was resistant to five antibiotics. The feline isolate was resistant to eight antibiotics. Combinations of antibiotic resistance determinants could be associated with large plasmids in UB5008 and UB4881 (human isolates) and UB1 146 (environmental isolate), which transferred $\mathrm{Km}^{\mathrm{R}}$ $\mathrm{Tc}^{\mathrm{R}}$ plasmids of about $120 \mathrm{MDa}$ in genetic crosses to E. coli J53-2: Plasmid transfer was detected only at $30^{\circ} \mathrm{C}$ and not at $37^{\circ} \mathrm{C}$. Given the high molecular mass, thermosensitivity of transfer and associated tellurite resistance determinant, these plasmids were presumptively assigned to Incompatibility group H. Strain 


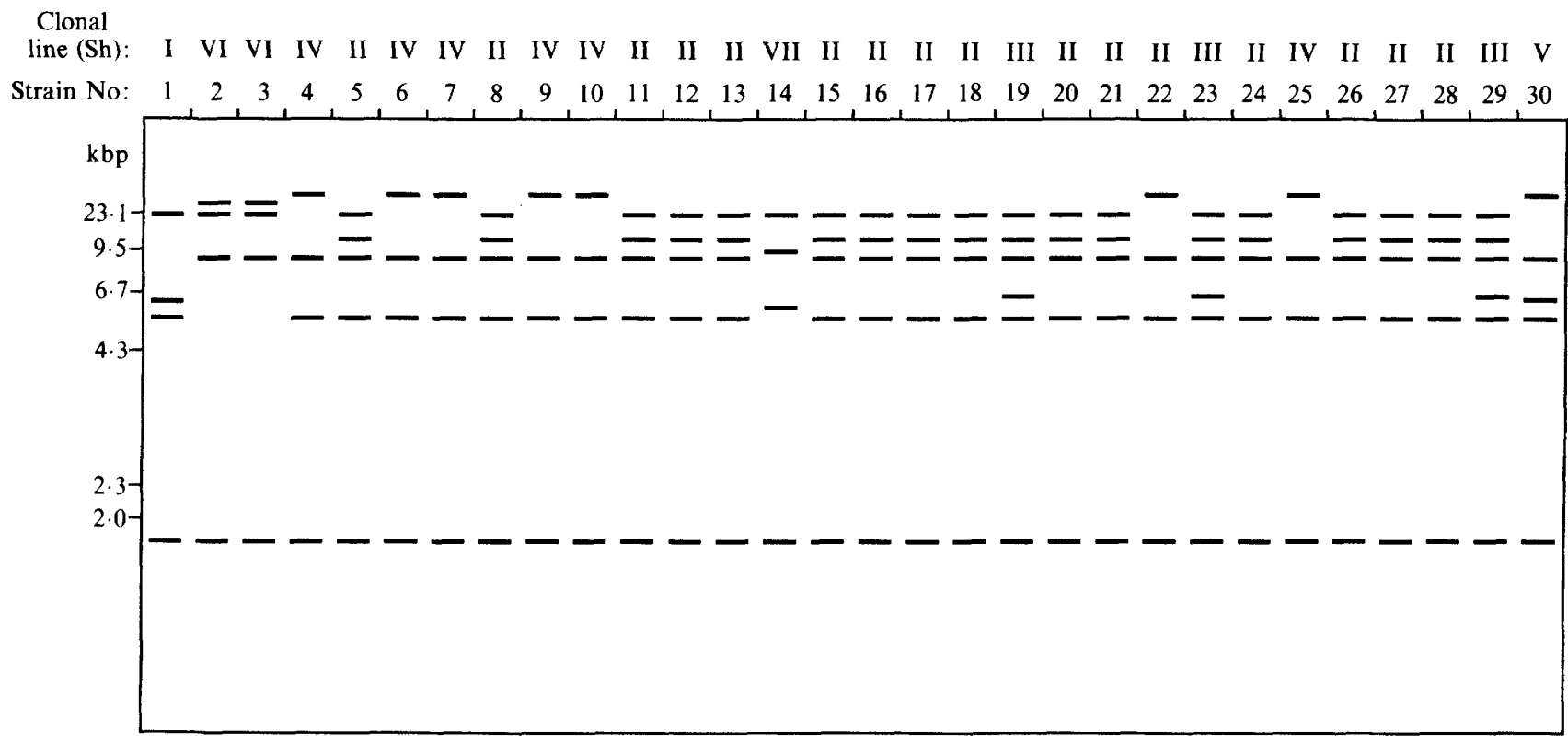

Fig. 2. Clonal lines of $S$. heidelberg and their IS200 fingerprints: diagrammatic representation of all strains analysed. Strains were analysed as listed in Table 1 . The IS 200 fingerprints confirmed from at least three genomic Southern blots (Pst $\mathrm{I})$ are shown. Molecular size markers shown on the left were HindIII fragments of bacteriophage lambda. Assigned clonal lines are indicated in roman numerals above the strain numbers (ShI ... ShVII).

UB5443, a food isolate, transferred a $59 \mathrm{MDa} \mathrm{Ap}^{\mathrm{R}}$ plasmid to $\mathrm{J} 53-2$ at $37^{\circ} \mathrm{C}$. The five resistance determinants of the Mexican strain, UB5503, were associated with a $120 \mathrm{MDa}$ plasmid, whilst the three markers of UB5848, which shared IS200 fingerprint IV, were associated with a $58 \mathrm{MDa}$ plasmid. The resistance determinants of UB462, the only resistant chicken strain, were associated with a $59 \mathrm{MDa}$ plasmid.

As seen in Table 2, a striking feature of the plasmid analysis is that the eighteen strains assigned to the related IS200 fingerprint classes II and III contained combinations of low-molecular-mass cryptic plasmids not found in the other seven IS200 fingerprint groups: $0.8,1.0,1.2,1.5,2.0$, and $2.5 \mathrm{MDa}$. Fourteen strains, including ten out of eleven chicken-associated strains, carried a 23 MDa cryptic plasmid (Table 2). Four other strains (UB898, 6333, 1631, and 2775) carried this plasmid and were contemporary isolates from animals and humans presumably infected from a chicken source. Three members of the related IS 200 fingerprint groups II/III lacked the $23 \mathrm{MDa}$ plasmid. These strains, UB5433, UB5542 and UB1146, were not associated with chicken, but were food or water isolates. They did, however, contain the aforementioned low-molecularmass cryptic plasmids. The profiles of cryptic plasmids permitted subdivision of IS200 fingerprint groups II/III.

Hybridization experiments were carried out with replicate filters. No homology with the $23 \mathrm{MDa}$ plasmid of IS200 fingerprint groups II/III, or with any other plasmid, was found for a VirA probe, the cloned virulence region of the $S$. typhimurium virulence plasmid (see Table 1). In all strains, it was found that this $23 \mathrm{MDa}$ plasmid was homologous (data not shown) to a probe for the basic replicon of Incompatibility group X. An FIC probe hybridized to six plasmids of between 42 and $68 \mathrm{MDa}$, as shown in Table 2, thereby identifying them as belonging to the $\mathrm{F} / \mathrm{I}$ complex (Couturier et al., 1989). No hybridization to any $S$. heidelberg plasmid was detected with IS200, including to the transferable $R$ plasmids.

\section{Clonal lines of $S$. heidelberg}

Seven unique IS200 fingerprints were detected among the $S$. heidelberg strains analysed. Since no IS200 insertion sites were detected in any plasmid, these were chromosomal fingerprints, subject largely to vertical inheritance. Additional evidence that unique fingerprints correspond to unique genotypes was provided by the distribution of plasmids within the strain set. This occurred along divisions of the chromosomal IS200 fingerprint. For example, strains with fingerprint II and III were all distinguished by the carriage of a $23 \mathrm{MDa}$ plasmid, and/or combinations of small cryptic plasmids not found in strains with other fingerprints, such as group IV. For these reasons, the observed IS200 fingerprints were taken to define clonal lines of $S$. heidelberg (see also Discussion below). 
Table 2. Plasmid analysis

\begin{tabular}{|c|c|c|c|c|c|}
\hline $\begin{array}{l}\text { Clonal } \\
\text { line }\end{array}$ & $\begin{array}{c}\text { Strain } \\
\text { number }\end{array}$ & $\begin{array}{l}\text { IS200 } \\
\text { copy } \\
\text { number }\end{array}$ & $\begin{array}{c}\text { IS200 } \\
\text { PstI } \\
\text { fragment } \\
\text { sizes } \\
\text { (kbp) }\end{array}$ & $\begin{array}{l}\text { Antibiotic } \\
\text { resistances }\end{array}$ & $\begin{array}{c}\text { Plasmid } \\
\text { content } \\
\text { (MDa sizes) }\end{array}$ \\
\hline ShI & 5717 & 4 & $\begin{array}{l}2 \cdot 0 \\
6.3 \\
5 \cdot 5 \\
1.7\end{array}$ & & \\
\hline ShII & $\begin{array}{r}5433 \\
5542 \\
6333 \\
321 \\
462 \\
198 \\
489 \\
541 \\
557 \\
898 \\
857 \\
1631 \\
1960 \\
2016 \\
2775\end{array}$ & 5 & $\begin{array}{l}20 \\
10 \cdot 1 \\
8 \cdot 6 \\
5 \cdot 5 \\
1 \cdot 7\end{array}$ & $\begin{array}{l}\text { Ap Sm Sp Su } \\
\text { Ap Sm Sp Su } \\
\text { Ap Sm Sp Su } \\
\text { Ap Cm Km Nm Sm Sp Su }\end{array}$ & $\begin{array}{l}59 \dagger, 10,8,1 \cdot 2,0 \cdot 8 \\
59 \dagger, 8,1 \cdot 2,0 \cdot 8 \\
23^{*}, 1 \cdot 2 \\
1 \cdot 2 \\
59 \dagger, 23^{*}, 2 \\
23^{*}, 1 \cdot 5 \\
23^{*}, 1 \cdot 5 \\
42 \dagger, 23^{*}, 1 \cdot 5 \\
23^{*}, 2,1 \\
110,23^{*}, 2,1 \\
23^{*}, 1 \cdot 2,0 \cdot 8 \\
23^{*}, 2,1 \\
23^{*}, 1 \cdot 2 \\
23^{*}, 2,1 \\
23^{*}, 2,1\end{array}$ \\
\hline ShIII & $\begin{array}{r}787 \\
1146 \\
2868\end{array}$ & 6 & $\begin{array}{l}20 \\
10 \cdot 1 \\
8 \cdot 6 \\
6.5 \\
5.5 \\
1.7\end{array}$ & $\mathrm{Cm} \mathrm{Km} \mathrm{Nm} \mathrm{Sm} \mathrm{Sp} \mathrm{Su} \mathrm{Tc}$ & $\begin{array}{l}23^{*}, 2,1 \\
110,10,2,1 \cdot 5 \\
23^{*}, 2 \cdot 5,2,1\end{array}$ \\
\hline ShIV & $\begin{array}{r}5051 \\
5445 \\
5503 \\
5848 \\
6228 \\
988 \\
1764\end{array}$ & 4 & $\begin{array}{r}\sim 30 \\
8 \cdot 6 \\
5.5 \\
1.7\end{array}$ & $\begin{array}{l}\text { Sm Su Tc } \\
\text { Cm Sm Sp Su Tc } \\
\text { Sm Sp Su } \\
\text { Sm Su Tc }\end{array}$ & $\begin{array}{l}8,1 \cdot 8 \\
68 \dagger, 3 \cdot 5 \\
120,4 \\
58 \dagger \\
56,8,1 \cdot 8\end{array}$ \\
\hline ShV & 3069 & 5 & $\begin{array}{r}\sim 30 \\
8.6 \\
6.4 \\
5.5 \\
1.7\end{array}$ & & 56,4 \\
\hline ShVI & $\begin{array}{l}4881 \\
5008\end{array}$ & 4 & $\begin{array}{r}\sim 26 \\
20 \\
8 \cdot 6 \\
1 \cdot 7\end{array}$ & $\begin{array}{l}\mathrm{Km} \mathrm{Nm} \mathrm{Su} \mathrm{Tc} \\
\mathrm{Km} \mathrm{Nm} \mathrm{Su} \mathrm{Tc}\end{array}$ & $\begin{array}{l}120 \\
120\end{array}$ \\
\hline ShVII & 378 & 4 & $\begin{array}{l}20 \\
9.8 \\
5 \cdot 8 \\
1 \cdot 7\end{array}$ & & \\
\hline
\end{tabular}

* Plasmid homologous to Inc $X_{\mathrm{R} 485}$.

† Plasmid homologous to IncFIC.

\section{Discussion}

In the present report we have analysed the copy number and distribution of IS200 in order to differentiate and characterize chromosomal genotypes within $S$. heidelberg. No intraserovar subtyping method, such as phage typing, presently exists for S. heidelberg, and IS200 fingerprinting is therefore an appropriate and valuable epidemiological tool for this serovar. A number of other Salmonella serovars, of similar importance to $S$. heidelberg in human salmonellosis, also lack intraserovar subtyping methods. Candidates for a molecular approach to epidemiology by IS200 fingerprinting include $S$. hadar, $S$. infantis, $S$. montivideo, $S$. newport, $S$. bredeney, $S$. kedougou and $S$. panama (Anon, 1991). The discriminatory power of the method was greater 
within $S$. heidelberg (Serogroup B) than was the case for $S$. enteritidis (Serogroup D1). For S. enteritidis, the major causative agent of non-typhoid salmonellosis in the UK and many other countries, a discriminatory phage typing scheme has been developed (Ward et al., 1987), and the type strains of this scheme exhibited an IS200 copy number of two and fell into three clonal lines defined by IS200 fingerprint (Stanley et al., 1991). The discriminatory value of IS200 fingerprinting apparently depends in the first instance on the copy number of the element, which varies within specific limits for a given serovar. Among even the present (limited) sample of $S$. heidelberg, where the minimum IS200 copy number was four, seven unique fingerprints were detected.

We conclude that IS200 fingerprints of $S$. heidelberg are stable, vertically inherited, and superior to plasmids for the analysis of genetic relationships. Nonetheless, results presented in this report also suggest that IS200 fingerprinting may be usefully complemented by plasmid analysis. A balanced picture of clonal relationships within a serovar may be gained, and IS200-defined clonal lines may themselves be subtyped by the presence of combinations of plasmids. For example if clonal line ShII (Table 2) is examined for plasmids smaller than and including the $23 \mathrm{MDa}$ plasmid, eight plasmid profiles can be discerned among its fifteen members. If larger plasmids are included, eleven plasmid profiles subdivide ShII.

Some other features of the plasmid analysis were of general significance. A $23 \mathrm{MDa}$ IncX plasmid was exclusively found in chicken and chicken-associated strains of ShII/III, and was absent from non-chicken strains of these clonal lines, such as UB5433, UB5542 or UB1146. It is possible that this IncX plasmid could carry host-specificity determinants for chicken, and in any event, it is a specific marker for strains of chicken origin. Again, it was noteworthy that no homology to Salmonella plasmid virulence (Spv) genes encoded by the $4.1 \mathrm{kbp}$ EcoRI VirA fragment of the $S$. typhimurium 'virulence plasmid' was detected. Since many strains examined, occurring in two different clonal lines, (predominantly ShIV) were septicaemic, this result may suggest that Spv genes, whose function has been defined by ability to multiply in the reticuloendothelial system of the BalbC mouse, have no relevance for septicaemic invasion in humans. A noticeable finding was that no plasmid copies of IS200 were detected. In their investigation of six E. coli insertion sequences, Sawyer et al. (1987) found $10 \%$ of all IS bands were contained in plasmids. These $E$. coli elements also differed in their occurrence in plasmid loci, from $3 \%$ of total insertions for IS4 to $16 \%$ for IS5. Although insertions of IS200 were previously observed in S. enteritidis plasmids (Stanley et al., 1991), this element shows no preference for $S$. heidelberg plasmids. This factor, and the consequent lack of lateral distribution, may have influenced the relative copy number stability of IS200 within and between Salmonella serovars. Conservation of serovar specific IS 200 profiles is a feature of $S$. heidelberg in this analysis, and of $S$. enteritidis and S. typhimurium (Stanley et al., 1991, $1992 a, b)$ and reflects intermediate-term evolutionary relationships. Furthermore, IS200 was not found in the large IncH and $\mathrm{F} / \mathrm{I}$ complex plasmids in this analysis. These plasmids represent the major vectors of transferable antibiotic resistance in Salmonella, suggesting that this insertion sequence is not generally disseminated by 'hitchhiking' in transferable plasmids.

We consider that these IS200 fingerprints represent clonal lines of $S$. heidelberg for the following reasons. Firstly, since insertions of IS200 in plasmids could be discounted, the $S$. heidelberg fingerprints differentiated loci which are inherited in accordance with the definition of clonality (Orskov \& Orskov, 1983) as being of common chromosomal genetic origin. Genetic mapping showed that the six IS200 insertions in the $S$. typhimurium LT2 chromosome were quite evenly spaced (Lam \& Roth, 1983), and there is no reason to believe that this is not the case for these $S$. heidelberg strains. Secondly, the distribution of plasmids in the concurrent analysis suggested that plasmid distribution was subject to hostspecific restrictions, and therefore that there were genotypic differences in this respect between clonal lines ShII/III and ShIV/V (and between these and clonal lines ShI, ShVI and ShVII).

When the reference (ECOR) collection of natural isolates of $E$. coli (Selander et al., 1987) was examined by Sawyer et al. (1987) for the distribution of six E. coli insertion sequences, strains that were electrophoretically identical at 35 enzyme loci shared only $43 \%$ of their insertion sequence bands. Strains that differed in one enzyme locus shared $28 \%$ of insertion sequence bands, and strains that differed in two or more enzymes shared no insertion sequence bands. The authors therefore hypothesized that insertion sequence numbers and positions change much more rapidly in evolution than do electrophoretic mobilities of proteins, remarking that insertion sequence comparisons might be useful in analysing the phylogenetic history of related strains, and for highly precise strain identification in epidemiology (Sawyer et al., 1987). For $S$. heidelberg and IS200, this indeed appears to be so. A survey of $204 S$. heidelberg isolates from global sources detected eight genotypes by multilocus enzyme electrophoresis (MLEE) which monitored changes at 23 enzyme loci (Beltran et al., 1988). By contrast, in the present limited sample number, seven genotypes were detected among only 30 strains by fingerprinting a single insertion sequence, IS200.

We hypothesize that IS200 fingerprinting is comp- 
lementary to MLEE analysis for phylogenetic purposes, defining short-term as well as intermediate-term evolutionary relationships. For reasons of its greater discriminatory power and relative technical simplicity, it is probably the more suitable of the two methods for epidemiological applications. We suggest that IS200 can provide a general purpose probe for epidemiological and genetic studies of many Salmonella serovars. This would avoid the necessity of developing many unique phenotypic subtyping schemes and could be employed in relation to a band matching database of serovars and their (intra-serovar) clonal lines.

The project was initiated with support from the British Council. We thank Dr Morag Timbury for encouraging the development of insertion sequence fingerprinting of current Salmonella pathogens. N.P. is a British Industries Research Fund (1991/92) student.

\section{References}

Anonymous. (1991). PHLS Communicable Disease Report 1(36), 162. Ayroza-Galvao, P. A., Milstein, K. T. M., Mimica, I. M., Maassen, S., Barbosa, J. S., CavalCante, N. J., Lorenco, R., Mimica, L. M. \& MARTINo, M. D. (1989). Aztreonam in the treatment of bacterial meningitis. Chemotherapy 1, 39-44.

Beltran, P., Musser, J. M., Helmuth, R., Farmer, J. J., Frerichs, W. M., WACHSMUth, I. K., FerRIS, K., MCWhORTER, A. C., Wells, J. G., Cravioto, A. \& Selander, R. K. (1988). Towards a population genetic analysis of Salmonella. Proceedings of the National Academy of Sciences of the United States of America 85, 7753-7757.

Chol, M., Yoshikawa, T. T., Bridge, J., SChlaifer, A., Oster WeIL, D., Reid, D. \& Norman, D. C. (1990). Salmonella outbreak in a nursing home. Journal of the American Geriatrics Society 38(5), 531-534.

Couturier, M., Bex, F., Berquist, P. L. \& MaAs, W. K. (1988). Identification and classification of bacterial plasmids. Microbiological Reviews 52, 375-395.

GiberT, I., BARBE, J. \& CASADESUS, J. (1990). Distribution of insertion sequence IS200 in Salmonella and Shigella. Journal of General Microbiology 136, 2555-2560.

Gibert, I., Carroll, I., Hillyard, D. R., Barbe, J. \& Casadesus, J. (1991). IS 200 is not a member of the IS600 family of insertion sequences. Nucleic Acids Research 19, 1343.

Harris, A. A., Cherubin, C., Biek, R. \& Edwards, L. C. (1990). Frequency of Salmonella typhimurium the year after a massive outbreak. Diagnostic Microbiology and Infectious Disease 13, 25-30.

Heal, J. M., Jones, M. E., Forey, J., Chaudhry, A. \& STricof, R. L. (1987). Fatal Salmonella septicemia after platelet transfusion. Transfusion 27, 2-5.
KADO, C. I. \& LIU, S.-T. (1981). Rapid procedure for detection of large and small plasmids. Journal of Bacteriology 145, 1365-1375.

LAM, S. \& RoTH, J. R. (1983). IS200: a Salmonella-specific insertion sequence. Cell 34, 951-960.

Norel, F., Coynault, C., Miras, I., Hermant, D. \& Popoff, M. Y. (1989). Cloning and expression of plasmid DNA sequences involved in Salmonella serotype typhimurium virulence. Molecular Microbiology 3, 733-743.

O'Reilly, C., BlaCK, G. W., LAfFey, R. \& McConnell, D. J. (1990). Molecular analysis of an IS 200 insertion in the gpt gene of Salmonella typhimurium. Journal of Bacteriology 172, 6599-6601.

ORSKOV, F. \& ORSKOV, I. (1983). Abstract of a workshop on the clone concept in the epidemiology, taxonomy, and evolution of the Enterobacteriaceae and other bacteria. Journal of Infectious Diseases 148, 346-357.

Rice, P. A., Craven, P. C. \& Wells, J. G. (1976). Salmonella heidelberg enteritis and bacteremia. American Journal of Medicine 60 , 509-515.

Sambroox, J., Fritsch, E. F. \& Maniatis, T. (1989). Molecular Cloning: a Laboratory Manual. Cold Spring Harbor, NY: Cold Spring Harbor Laboratory.

Sawyer, S. A., Dykhuizen, D. E., Dubose, R. F., Green, L., Mutangadura-MHLanga, T., WolczYK, D. F. \& HaRTL, D. L. (1987). Distribution and abundance of insertion sequences among natural isolates of Escherichia coli. Genetics 115, 51-63.

Selander, R. K., Caugant, D. A. \& Whittam, T. S. (1987). Genetic structure and variation in natural populations of Escherichia coli. In Escherichia coli and Salmonella typhimurium Cellular and Molecular Biology. Edited by F. C. Neidhardt, J. L. Ingraham, K. B. Low, B. Magasanik, M. Schaechter \& H. E. Umbarger. Washington DC: American Society for Microbiology.

Stalker, D. M. \& Helinski, D. R. (1985). DNA segments of the IncX plasmid R485 determining replication and incompatibility with R6K. Plasmid 14, 245-254.

Stanley, J., JoNes, C. S. \& Threlfall, E. J. (1991). Evolutionary lines among Salmonella enteritidis phage types are identified by insertion sequence IS200 distribution. FEMS Microbiology Letters 82, 83-90.

Stanley, J., Burnens, A. P., Threlfall, E. J., Chowdry, N. B. \& GOLDSWORTHY, M. (1992a). Genetic relationships among strains of Salmonella enteritidis in a national epidemic in Switzerland. Epidemiology and Infection 108, 213-220.

Stanley, J., Goldsworthy, M. \& Threlfall, E. J. (1992b). Molecular phylogenetic typing of pandemic isolates of Salmonella enteritidis. FEMS Microbiology Letters 90, 153-160.

Threlfals, E. J. \& Frost, J. A. (1990). The identification and fingerprinting of Salmonella : laboratory aspects and epidemiological applications. Journal of Applied Bacteriology 68, 5-16.

Threlfall, E. J., Hall, M. L. M., Ward, L. R. \& Rowe, B. (1992). Plasmid profiles demonstrate that an upsurge of Salmonella berta in humans in England and Wales is associated with imported poultry meat. European Journal of Epidemiology 8, 27-33.

WARD, L. R., DE SA, J. D. H. \& RoWE, B. (1987). A phage typing scheme for Salmonella enteritidis. Epidemiology and Infection 99, 291-294.

WILson, K. (1987). Preparation of genomic DNA from bacteria. In Current Protocols in Molecular Biology, Unit 2.4.1. Edited by F. M. Ausubel, R. Brent, R. E. Kingston, D. D. Moore, J. A. Smith, J. G. Seidman \& K. Struhl. New York: Wiley. 